\title{
Dengeli Puan Kartıyla Performans Ölçümü: Bir Denetim Şirketi Uygulaması
}

R. Şebnem YAŞAR*

\section{ÖZET}

Çok boyutlu performans ölçüm yöntemleri, geleneksel performans ölçüm yöntemlerinin eksiklerini gidermek amacıla finansal verilerin yanında finansal olmayan verileri de kullanarak tam bir değerleme imkânı sunan sistemlerdir. Dengeli Puan Kartı (DPK), çok boyutlu performans ölçüm yöntemlerinden bir tanesidir. Örgütsel strateji ile operasyonel ölçütleri birbirine bağlayan bir çerçeve içinde, geleneksel performans ölçütlerini gelecekteki finansal performansin temel göstergeleriyle bir araya getiren DPK, bir performans ölçüm ve yönetim sistemi olarak değer kazanmış, strateji geliştirme ve değerlendirme süreçleri için temel bir organizasyon aracı haline gelmiştir. Hizmet sektöründe çıktıların soyut verilere dayanması ve buna bağll olarak performans ölçümünün zorluğu nedeniyle, çok boyutlu yöntemlerden yararlanılmaktadır. Bu çalışmada, denetim şirketlerinde DPK yaklaşımı ile performans ölçümüne ilişkin bir uygulama yapılmıştır.

Anahtar Kelimeler: Dengeli Puan Kartı, Çok Boyutlu Performans Ölçümü, Performans Ölçümü, Performans Değerleme.

JEL Sinıflandirması: L25, M41, M42

\section{Performance Measurement Using Balanced Scorecard: A System Implementation in} an Audit Firm

\section{ABSTRACT}

Multi-dimensional performance measurement systems offer a full valuation by using non-financial data alongside financial data in order to overcome the shortcomings of traditional methods of performance measurement. Balanced Scorecard (BSC) is one of the multi-dimensional performance measurement methods. By a framework linking operational metrics to organizational strategy, BSC combines traditional performance metrics with basic indicators of future financial performance. As a result, it has been appreciated as a performance measurement and management system, and has become an essential organizational tool for strategy development and evaluation processes. Multi-dimensional performance measurement methods are utilized in the service sector due to the intangibility of the output and difficulty of performance measurement accordingly. In this study, an implementation of BSC in audit firms has been conducted.

Keywords: Balanced Scorecard, Multi-Dimensional Performance Measurement, Performance Measurement, Performance Evaluation

JEL Classification: L25, M41, M42

\footnotetext{
* Öğr. Gör. Dr. R. Şebnem Yaşar, Dokuz Eylül Üniversitesi, İzmir Meslek Yüksekokulu, Muhasebe ve Vergi Uygulamaları Programı, sebnem.yasar@deu.edu.tr
} 


\section{GİRiş}

Artan rekabet ve değişen talep yapısı, stratejilerini ve yönetim sistemlerini tekrar gözden geçirmek ve geliştirmek yönünde işletmeleri zorlamaktadır (Striteska ve Spickova, 2012: 277). İş mükemmelliğinde gelişmek ve sonuçta başarıya ulaşmak için ilk koşul, bir performans ölçümü ve yönetimi sistemi geliştirmek ve uygulamaktır (Kanji, 2002: 715). Bu nedenle stratejik yönetim ve performans ölçüm sorunlarına özel önem verilmektedir.

Profesyonel denetçiler tarafindan diğer şirketlere ve kurumlara hizmet veren profesyonel örgütler olan denetim şirketleri, son yıllarda hizmet sektörünün en önemli yapıtaşlarından biri haline gelmişlerdir. Bu şirketlerin en önemli girdisi çalş̧anların bilgi ve becerileri, bir başka ifadeyle insan sermayesidir. Denetim şirketlerinin sahip oldukları insan sermayesi, denetçilerin uzmanlık ve deneyimleri ile somutlaşır ve şirket performansının belirlenmesinde önemli bir girdiyi teşkil eder. Dolayısıyla performansın geliştirilmesi için, sunulan çıktının yanı sıra girdilere de eşit derecede önem verilmesi gerekmektedir. Ayrıca, denetim şirketlerinde hizmet üretim sürecinin çıktıları olan denetim raporları, diğer şirketlerin süreçleri için girdi konumundadır. Bu durum, denetim şirketlerinde müşteriye çok önemli bir rol biçmekte ve müşteri memnuniyetinin sağlanması kritik bir başarı faktörü olmaktadır. Bu unsurlar, denetim şirketlerinin performans ölçümünde yalnızca finansal ölçütlerin kullanılmasının yeterli olmayacağını göstermektedir.

Finansal olmayan performans ölçütlerinin yükselişi, özellikle son yirmi yıldır hız kazanmıştır. Dinamik bir ortamda finansal performans ölçütlerinin işletmelerin beklentilerini tam olarak karşılamayabilecekleri gerçeğinin anlaşılması, yönetsel faaliyetlerin uzun dönemli etkilerini yansıtmaya odaklanan yeni yöntemlerin ortaya çıkmasına yol açmıştır (Budde, 2007: 515). Bu yeni kavramların en göze çarpanı olan DPK, finansal ve finansal olmayan başarı ölçütlerini işletme stratejisine bağlayan bir çerçeve sunmaktadır (Kaplan ve Norton, 1996c: 24).

Bu çalışmada, DPK yöntemi bir denetim şirketinde uygulanmış ve sonuçları ortaya konulmuştur. DPK uygulamalarına ilişkin olarak, literatürde pek çok çalışma bulunmaktadır. Ancak bu çalışmalarda hizmet sektöründeki uygulamalar üzerinde pek fazla durulmamış, genellikle üretim sektörüne odaklanılmıştır. Bu bağlamda çalışmanın, kullanılan yöntem ve uygulandığı sektör açısından literatüre katkı sağlayacağı düşünülmektedir.

\section{PERFORMANS ÖLÇÜMÜ}

Performans genel olarak, bir amacın gerçekleştirilme derecesi olarak tanımlanabilir. Örgütsel performans, stratejik yönetimin en önemli yapı taşıdır. Performans ölçümüne ilişkin pek çok araştırma yürütülmüş olmasına rağmen, performans ölçümünün tanımı hâlâ tartışılmaktadır. Moullin'e göre (2007: 181) en çok ortaya konulan performans ölçümü tanımı, Neely'nin (2002) "geçmiş eylemlerin verimlilik ve etkinliğini nicelleştirme süreci" tanımıdır. Bu tanım, verimliliğin yanı sıra etkinliğe vurgu yapmakta, ancak neyin ölçüldüğünü ya da neden ölçüldüğünü belirtmemektedir (Striteska ve Spickova, 2012: 278). İşletmelerin 
müşterilerine sağladığı değerlerin ölçümüne vurgu yaparak daha iyi bir rehber görevi gören başka bir tanım Moullin (2007: 181) tarafından yapılmış ve performans ölçümü, "örgütlerin ne derecede iyi yönetildiklerinin ve paydaşlara sağladıkları değerlerin ölçümü” şeklinde ifade edilmiştir.

1980'lerin ortalarından itibaren, bilgi teknolojileri, yenilikçi ürünler ve artan rekabet gibi örgütsel çevrede oluşan gelişmeler, örgütlerin işleyiş şekillerini belirgin şekilde değiştirmiş̧tir. Paydaşlar için değer yaratımı, yöneticiler için önemli bir odak noktası haline gelmiştir. Bu değişiklikler aynı zamanda, bireysel paydaş kapsamının ötesinde performansı ölçmeye yönelik sistematik bir yaklaşım ve sık1 yönetim kontrol sistemlerini gerektiren stratejik planlama süreci ile bütünleşik ölçüm ihtiyacının, akademisyenler ve uygulamacılar tarafından ele alınmasına yol açmıştır (Upadhaya vd., 2014: 853). Performans ölçüm sisteminin önemli bir unsur olduğu yeterli ve uygun bir yönetim kontrol sistemi olmaksızın, örgütlerin başarısızlık riski altında olmaları kaçınılmazdır. Bir başka ifadeyle, günümüzün artan rekabet koşullarında işletmelerin başarılı olabilmeleri ve hayatta kalabilmeleri, etkin bir performans ölçüm sistemine sahip olmalarıyla yakından ilişkilidir. Yeterli ve uygun bir performans ölçüm sistemi, örgütleri potansiyel risklerden ve zararlardan koruyabilir ve örgütsel etkinliği artırabilir (Upadhaya vd., 2014: 853). Performans ölçümü sadece denetim amaçlı değil aynı zamanda gelişmeye yönelik bir süreç olarak algılanmalıdır.

\section{PERFORMANS ÖLÇÜTLERİ}

Geleneksel olarak, performans ölçümünün odağında finansal ölçütler yer almaktadır (Striteska ve Spickova, 2012: 278). Geleneksel örgütler, faaliyetlerinin performansinı değerlendirmek için finansal ölçütlere aşırı bağımlılık göstermektedirler (Upadhaya vd., 2014: 854). Aktif kârlılığı, yatırım kârlılığı, hisse başına kâr gibi finansal ölçütler, örgütlerin işletim ve finansal başarısını ya da başarısızlığını ölçmek için yaygın olarak kullanılmaktadırlar (Chenhall ve Langfield-Smith, 1999: 38; Otley, 2001: 245). Finansal ölçütler, hem en kolay anlaşılan ve en somut ölçütler olmaları dolayısıyla karar alma sürecini kolaylaştırmaları, hem de subjektifliği ve göstergelerin sonuçları üzerindeki tartışmaları ortadan kaldırmalarıyla tercih edilmektedirler (Yükçü ve Atağan, 2010: 28).

$\mathrm{Bu}$ yaygın kullanıma rağmen, performans ölçümü ve değerlemesinde yalnızca finansal ölçütlerin kullanılması birçok araştırmacı tarafından eleştirilmektedir. Örneğin, Evan (1976: 25) "hisse başına kazanç, yatırım kârlılığı, brüt kâr marjı gibi ölçütler, çıktıyı ya da girdi ile çıktı arasındaki ilişkiyi vurgulamakta ancak, dönüşüm süreçlerini ve geribildirim etkisini görmezden gelmektedir" yorumunu yapmaktadır. Bu ölçütler, öncelikle maliyet, gelir ve kâra odaklanarak, geçmişte gerçekleştirilmiş olan faaliyetlerin finansal sonuçlarını ortaya koymaktadırlar. Bunun sonucu olarak, esas olarak maliyetlerin düşürülmesi üzerine yoğunlaşmakta, gelecekteki faaliyetleri geliştirmeye yönelik sınırlı bir yönlendirme sağlamaktadırlar (Upadhaya vd., 2014: 854). Yalnızca tarihsel muhasebe verilerine dayanan bu retrospektif yaklaşım, örgütleri gelişmeye yöneltmediği, hatta bazen gelişmeyi engellediği gerekçesiyle yalnızca araştırmacılar tarafından değil, aynı zamanda uygulamacılar tarafından 
da eleştirilmiştir. (Aureli, 2010: 83; Kaplan ve Norton, 1992: 77; Atkinson vd., 2012: 18). Yalnızca finansal ölçütlerin kullanılmasının, yöneticileri ürün kalitesi, personel eğitimi gibi maliyet yaratan eylemlerden kaçinarak kısa vadeli kârı arttrrmaya yönelik bir çaba içine sokacağı, bunun da uzun vadede örgütsel etkinlik üzerinde olumsuz etkilere yol açabileceği düşünülmektedir (Upadhaya vd., 2014: 854). Bir başka ifadeyle finansal ölçütlerin, kısa vadeli sonuçlara odaklanmaları sonucunda, uzun vadeli örgütsel etkinliği görmezden gelerek kısa vadeli davranışları ödüllendirdikleri düşünülmektedir.

Ancak 1980'lerin sonlarına doğru bu durum değişmeye başlamıştır. Bu dönemde yapılan çalışmalar, işletmelerin rekabet ettiği pazarların artan karmaşıklı̆̆ı nedeniyle, tarihi finansal verilerin performans ölçümü için yeterli olmadığını göstermiştir (Kennerley ve Neely, 2002: 1223). Bunun sebebi, finansal raporların artık yeterli paydaş değeri göstergeleri olmamalarıdır. Sürdürülebilir paydaş değerine, müşteri sadakati, çalışan memnuniyeti, içsel iş süreçleri ve örgütsel yenilik gibi finansal olmayan unsurlar ile ulaşlabilmektedir (Striteska ve Spickova, 2012: 278). Johnson ve Kaplan (1987) tarafindan yazılan "Relevance Lost - The Rise and Fall of Management Accounting" adlı kitap, geleneksel performans ölçümlerini, sürekli iyileştirme yerine sapmaların minimize edilmesine odaklanmaları nedeniyle eleştirerek, daha iyi entegre performans ölçümlerine olan ihtiyacı vurgulamaktadır (Gomes vd., 2004: 522). Benzer gerekçelerle, McNair ve Mosconi (1987: 28), daha iyi entegre performans ölçüm sistemlerinin geliştirilmesi gerekliliğini belirterek, finansal ve finansal olmayan ölçütlerin uyumlaştırılmaları gereğinin altını çizmişlerdir. Santori ve Anderson (1987: 141), finansal olmayan ölçütlerin, örgütteki işgücünün gelişiminin izlenmesi ve motive edilmesi açısından önemini vurgulamışlardır. Bütün bu gelişmelerin sonucu olarak, geleceğe dönük finansal olmayan ölçütlere olan vurgu artmış, performans ölçümünü daha geniş bir açıdan sunmayı amaçlayan bazı çerçeveler ortaya çıkmaya başlamıştır.

Sürekli gelişen teknolojik, düzenleyici ve rekabetçi çevre göz önüne alındığında yöneticilerin, müşteriler, çalışanlar, tedarikçiler, kredi verenler gibi birden fazla paydaşı aynı anda ve/veya birbirinden bağımsız olarak tatmin ederken, finansal ve finansal olmayan hedeflere ulaşmaları beklenmektedir. Bu paydaşların beklentileri büyük ölçüde birbirinden farklıdır ve başarı, bu farklı beklentilerin karşılanabilme derecesine bağlıdır (Striteska ve Spickova, 2012: 277). Örneğin, müşteriler kalitesi yüksek mal ya da hizmetleri düşük fiyata satın alma, çalışanlar ücret artışı, devlet kurumları ise kanun ve yönetmeliklere uygun davranılması beklentisi içindedirler. Dolayısıyla, bir işletme yalnızca kendi ihtiyaçlarını karşılayan bir performans değerleme sistemi inşa edemez (Striteska ve Spickova, 2012: 277). Etkili bir örgüt, dış paydaşların farklı beklentilerini karşılarken, örgütsel hedeflere ulaşabilmek için çalışanlarını motive etmek zorundadır (Upadhaya vd., 2014: 854). Bu beklentiler finansal ölçütlerin kısıtlamaları ile birleştiğinde, çok yönlü ölçütler içeren performans ölçüm ve değerleme sistemleri örgütler için bir gereklilik haline gelmiştir.

Yalnızca finansal ölçütlerin kullanılmasının sınırlamaları, finansal ve finansal olmayan ölçütlerin bir karışımının kullanılması yönünde örgütleri teşvik etmiştir. Kaplan ve Norton 
(1992: 71), finansal ve finansal olmayan ölçütlerin birbirlerinin ikamesi olarak görülmemesi gerektiğini vurgulamakta, bunların kombinasyonunun istenilen sonuçları elde etmek için çok yararlı olduğunu belirtmektedirler. Finansal ve finansal olmayan ölçütlerin birlikte kullanılması, işletmelerin yüksek faaliyet performansına çok boyutlu bir şekilde erişimini mümkün kılmaktadır ve bu, örgütsel etkinliği sağlamak için en uygun yol olarak görülmektedir (Kaplan ve Norton, 1992: 71).

İşletmenin hangi performans ölçütlerini kullanacağı, bağgl olduğu sektöre, örgüt kültürüne ve misyonuna göre değişiklik göstermektedir. İşletme performans ölçütlerini oluştururken öncelikle vizyon, misyon ve stratejilerini belirlemeli ve daha sonra performans amaçlarını, ölçütlerini ve hedeflerini geliştirmelidir (Akgül, 2004: 74).

\section{PERFORMANS YÖNETIM SISTEMLERI}

Performans ölçümü ve performans yönetimi birbirinden farklı kavramlardır. Performans ölçümüne ilişkin literatür, performans yönetimine ilişkin literatürden çok daha kapsamlıdır (Striteska ve Spickova, 2012: 278). Performans yönetim sistemleri, işletmede alınan kararların, gerçekleştirilen faaliyetlerin ve işletmenin sahip olduğu kaynakların işletme stratejileriyle uyumunu sağlamak, dolayısıyla istenen sonuçlara ulaşabilmek ve paydaş değeri yaratmak amacıyla işletmelerin performanslarını planlamak, ölçmek ve kontrol etmek için tasarlanan sistemlerdir (Bento vd., 2013: 45). Performans yönetimi, bir örgütün kurumsal ve işlevsel stratejileri ve hedefleri ile kendi performansını entegre ettiği süreç olarak da tanımlanabilir (Bititci vd., 1997: 524). Performans ölçüm sistemlerinde ise, ölçüm sonucu elde edilen bilgilerin hizmet sunumunun değişimi ve geliştirilmesinde nasıl kullanılacağından ziyade, ölçüm sisteminin geçerliliğine odaklanılmaktadır (Striteska ve Spickova, 2012: 278). Performans yönetimi, performans ölçümü ile birlikte yönetim sisteminin bir unsuru olarak görülmelidir.

$\mathrm{Bu}$ bağlamda, Kennerley ve Neely'ye (2000: 149) göre performans yönetim sistemlerinin özellikleri aşağıda verilmektedir:

$\checkmark$ İşletme tarafindan kullanılan ölçütler işin 'dengeli' bir görüntüsünü vermelidir.

$\checkmark$ Ölçüm sistemi işletmenin performansının özünü ortaya koymalıdır

$\checkmark$ Performans ölçütleri çok boyutlu olmalıdır. İşletmenin başarısı için önemli olan tüm performans alanlarının ölçümünü içermelidir.

$\checkmark$ Performans ölçüm sistemi, kapsamlı bir haritalama yapmalıdır.

$\checkmark$ Performans ölçütleri, işletme fonksiyonlarına örgüt hiyerarşisi aracıllğıyla entegre edilmelidir.

$\checkmark$ Performans ölçüm sistemi, geçmiş performansın izlenmesi ve gelecekteki performansın planlanması için veri sağlamalıdır. Bu, ölçütlerin, hem sonuçları hem de bu sonuçları oluşturan unsurları ölçmesi gerektiği anlamına gelir. 
Son yirmi yıldır, etkili strateji uygulamaları için bir araç olarak performans yönetim sistemlerine olan ilgi artmıştır. Performans yönetimi çalışmalarının çoğu, stratejinin eyleme dönüştürülmesindeki rolüne odaklanarak, performans yönetimi sistemlerinin bu konuda özellikle işlevsel olduklarını teyit etmişlerdir (Striteska ve Spickova, 2012: 279).

\section{DENGELI PUAN KARTI}

Dengeli Puan Kartı (DPK), 1996 yılında, Harvard Business School'da muhasebe profesörü olan Robert Kaplan ile performans ölçümü ve örgütsel yenilenme konusunda uzmanlaşmış uluslararası bir danışmanlık firması olan Rönesans Solutions, Inc'in başkanı olan David Norton tarafından geliştirilmiş ve 1996 yılında sunulmuş bir performans ölçüm ve yönetim sistemidir. DPK, işletmenin her düzeyinde stratejileri tanımlamak, uygulamak ve yönetmek için kullanılan bir araçtır. Yönetim muhasebesinin en önemli gelişmelerinden biri olarak lanse edilen DPK, bir ölçüm sistemi, bir stratejik yönetim sistemi ve bir iletişim arac1 olarak, işletmelerin üç temel işlevini yerine getirmektedir (Striteska ve Spickova, 2012: 280).

\subsection{Dengeli Puan Kartı ile Performans Ölçümü}

Geleneksel yönetim sistemlerinin en önemli eksikliklerinden bir tanesi, işletmenin uzun vadeli stratejilerinin kısa vadeli eylemlerle bağlantısını kuramamalarıdır (Kaplan ve Norton, 1996a: 75). Çoğu şirketin operasyonel ve yönetim kontrol sistemleri, işletmenin uzun vadeli stratejik hedeflerine ulaşması üzerinde çok az etkisi olan finansal ölçütler ve hedefler etrafında inşa edilir. Dolayısıyla birçok şirketin kısa vadeli finansal ölçütlere verdiği önem, stratejinin gelişimi ile uygulaması arasında kopukluk oluşturur. DPK, şirketin performansının tek göstergesi olarak kısa vadeli finansal ölçütlere dayanmamaktadır. Aksine, kısa vadeli eylemler ile uzun vadeli stratejik hedeflerin ilişkilendirilmesine hem ayrı ayrı ve hem de bir bütün olarak katkı sağlayan dört farklı bakış açısı sunmaktadır (Kaplan ve Norton, 1996a: 75).

Yöntemin temelini, bir vizyonun ve işletme stratejisinin, finansal ve finansal olmayan performans göstergeleri ile sabit hedeflere detaylı olarak kodlanması ve uygulanması oluşturmaktadır. Bir başka ifadeyle DPK'nın uygulanması, hedeflerin, göstergelerin ve stratejik eylemlerin somut bakış açılarına ya da perspektiflere atanması anlamına gelmektedir (Striteska ve Spickova, 2012: 280).

DPK, performansı üç farklı açıdan daha ölçerek geleneksel finansal ölçütleri tamamlamaktadır. Bu yeni bakış açıları; müşteri, içsel iş süreçleri ile öğrenme ve büyüme boyutlarıdır (Kaplan ve Norton, 1996a: 75). Böylece, finansal boyutla kısa vadeli performansa olan ilgisini korurken, uzun vadeli finansal ve rekabetçi performans için yeni değer sürücüleri ortaya çıkarmaktadır (Kaplan ve Norton, 1996c: 8). Bir başka ifadeyle, işletmelerin büyüme için ihtiyaç duydukları yeteneklerdeki gelişimlerini ve maddi olmayan varlık edinimlerini izlerken, eşzamanlı olarak finansal sonuçları da görmelerini sağlamaktadır (Kaplan ve Norton, 1996a: 75). DPK, mevcut işletme performansının dengeli bir resmini ortaya koymanın yanı sıra, gelecekteki performansı artıracak unsurları da gözler önüne serer (Kaplan ve Norton, 1996c: 31). Buradaki denge kavramı; kısa vadeli ve uzun vadeli hedefler, gerekli girdiler ve 
çıktılar, iç ve dış performans faktörleri ile finansal ve finansal olmayan göstergeler arasındaki denge anlamına gelmektedir (Striteska ve Spickova, 2012: 280). Belirlenen performans boyutları, organizasyonun başarısı ile performans sürücüleri arasındaki bağlantının şeffaf bir görünümünü sunacak şekilde belirlenmişlerdir. Böylece, işletmeler mevcut strateji içinde esnek bir sistem kurabilmektedirler (Striteska ve Spickova, 2012: 280).

DPK, vizyon ve stratejiyi; finansal boyut, müşteri boyutu, içsel iş süreçleri boyutu ile öğrenme ve büyüme boyutunda gruplandırarak hedefler ve ölçütlere dönüştürür. Bu bağlamda, Kaplan ve Norton (1996c: 8) DPK'nın ölçütlerinin “örgütün vizyon ve stratejisinden türetildiğini” belirtmektedirler. DPK ile performans ölçümü yapılırken, her bir ölçüt grubu için, hedef performans seviyeleri ayarlanır, bu ölçütler için dönem içinde gerçekleşen fiili performans izlenir ve yönetsel performans değerlendirilir (Kaplan vd., 2012: 136).

Ancak şunu da belirmek gerekir ki, yönetsel yenilikler düzen bozucu (kesikli) değil sürdürülebilir (sürekli) olgulardır (Westphal vd., 1996: 249). Bir başka ifadeyle, yönetsel yenilikler yeni ve alışılmamış yöntemler içerse de, işletmenin rekabet avantajlarını geliştirmesini sağlayan sürdürülebilir yenilikler olmalıdır. Bu bağlamda, yönetsel yeniliklerin uygulama şekli işletmeden işletmeye farklılaşabilmektedir. Bir yönetsel yenilik olan DPK da örgütün üstüne göre dikilmesi gereken bir elbisedir. Bu bağlamda, Kaplan ve Norton tarafindan sunulan DPK modelinde yer alan boyutların, işletmenin mevcut yapısına ve rekabet koşullarına göre farklılaştırılarak ya da yeni boyutlar eklenerek işletmeye entegre edilmesi de mümkündür (Ax ve Bjornenak, 2005: 16).

\subsection{Dengeli Puan Kartı ile Performans Yönetimi}

DPK, finansal ve finansal olmayan ölçümlerin toplamından fazlasıdır. İşletme stratejisinin uzun vadeli stratejik hedefleri tanımlayan ölçütler kümesine dönüştürülmesinin yanı sıra, bu hedeflere ulaşılması ve bu hedeflere ilişkin geri bildirim alınması için kullanılan bir mekanizmadır (Kaplan ve Norton, 1996b: 68). Bu bağlamda DPK, bir performans ölçüm sistemi olmasının yanı sıra, bir performans yönetimi sistemi olarak da görülmektedir. DPK'nın, bir performans yönetim sistemi olarak başarısı temelde iki nedene dayandırılabilir.

Bunlardan birincisi, DPK'nın performans ölçümünün stratejiyle olan bağlantısına ve stratejinin hipotezlerini açıklayan sebep-sonuç bağlantılarına vurgu yapmasıdır. Ölçüm sistemi ile strateji arasındaki bağlantının sıkı olması, finansal olmayan ölçütlerin rolünü operasyonel bir kontrol listesi olmaktan çıkartarak, kapsamlı bir sistemin parçaları olmaya yükseltmiştir (Kaplan ve Norton, 2001: 87).

İkinci neden ise, DPK'nın teknolojinin ve rekabet üstünlügünün değişen yapısını yansıtmasıdır (Kaplan ve Norton, 2001: 87). Tüm dünyada işletmelerin bilgiye dayanan rekabete bağlı olarak kendilerini dönüştürmeleri sonucu, maddi olmayan varlıklardan yararlanma yetenekleri, maddi varlıklara yatırım yapma ve bunları yönetme yeteneklerinden çok daha belirleyici hale gelmiştir (Kaplan ve Norton, 1996a: 75). 19. yy’da ve 20. yy'1n 
büyük kısmında şirketler; stoklar, sınai tesisler ve ekipman gibi maddi varlıklara yaptıkları yatırımlarla ve bu varlıkları yönetme şekilleriyle rekabet üstünlüğü kazanmışlardır. Ancak 20. yüzyılın sonlarında, maddi olmayan varlıklar rekabet üstünlüğü için önemli bir kaynak haline gelmiştir. Değer yaratma stratejileri, maddi varlıkları iyi yönetmekten uzaklaşmış, işletmenin maddi olmayan varlıklar yaratması ve bunları etkin bir şekilde kullanması şeklinde ortaya çıkan bilgi tabanlı stratejilere kaymıştır. Bu stratejiler, bir yandan müşteri ilişkilerini, yenilikçi mal ve hizmetleri, kaliteli ve esnek işletme süreçlerini, çalışanların bilgi ve becerilerini, işgücünü destekleyen ve işletmeyi müşterilere ve tedarikçilere bağlayan bilgi teknolojilerini ve yenilikçiliği, diğer yandan sorunların çözümünü ve gelişimi teşvik eden örgüt iklimini kapsamaktadır (Kaplan ve Norton, 2001: 88). Ancak işletmeler maddi olmayan varlıklarının ölçümlerini yeterli düzeyde yapamamaktadırlar. İşletmeler tanımlayamadıkları ya da ölçemedikleri unsurları yönetemezler.

DPK, maddi varlıkları ve maddi olmayan varlıkları birbirine bağlayan değer yaratma stratejilerini tanımlayan yeni bir çerçeve ortaya koymuştur. DPK, işletmenin maddi olmayan varlıklarını değerleme için oluşturulmuş bir yöntem değil, bu varlıkların para dışında başka birimlerle ölçümünü yapan bir sistemdir (Kaplan ve Norton, 2001: 89). DPK, müşteri değer önerilerini farklılaştırmak ve üstün finansal sonuçlar elde etmek için maddi olmayan varlıkların nasıl harekete geçirilerek diğer maddi olmayan varlıklarla ve maddi varlıklarla birleştirileceğini açıklamaktadır (Kaplan ve Norton, 2001: 89).

Strateji liderliğinde oluşturulan ölçütler, finansal sonuçlara (uzun vadede kazanç ve büyüme) yol açan bir sebep-sonuç ilişkisi içinde birbiriyle ilişkilidir (Veltri, 2011: 8). Bu bağlamda DPK, bütünsel bir yaklaşımla tam bir yönetim sistemi olarak görülmektedir.

\subsection{Dengeli Puan Kartının Boyutları}

DPK'nın dört boyuttu bulunmaktadır. Bu boyutlar Şekil 1'de gösterilmektedir. DPK'da performans ölçümü ve değerlemesi yapılırken, bu dört boyuta ilişkin aşağıdaki sorulara yanıt aranmaktadır.

$\checkmark \quad$ Müşteriler işletmeyi nasıl görüyor? (Müşteri boyutu)

$\checkmark \quad$ Hissedarlar işletmeyi nasıl görüyor? (Finansal boyut)

$\checkmark \quad$ İşletmenin geliştirmesi gereken süreçleri hangileridir, işletme nerede üstün olmalıdır? (İçsel iş süreçleri boyutu)

$\checkmark \quad$ Değer yaratma ve iyileştirmenin sürekliliği nasıl sağlanabilir? (Öğrenme ve büyüme boyutu) 
Şekil 1. Dengeli Puan Kartı Boyutları (Kaplan ve Norton, 1996b: 54)

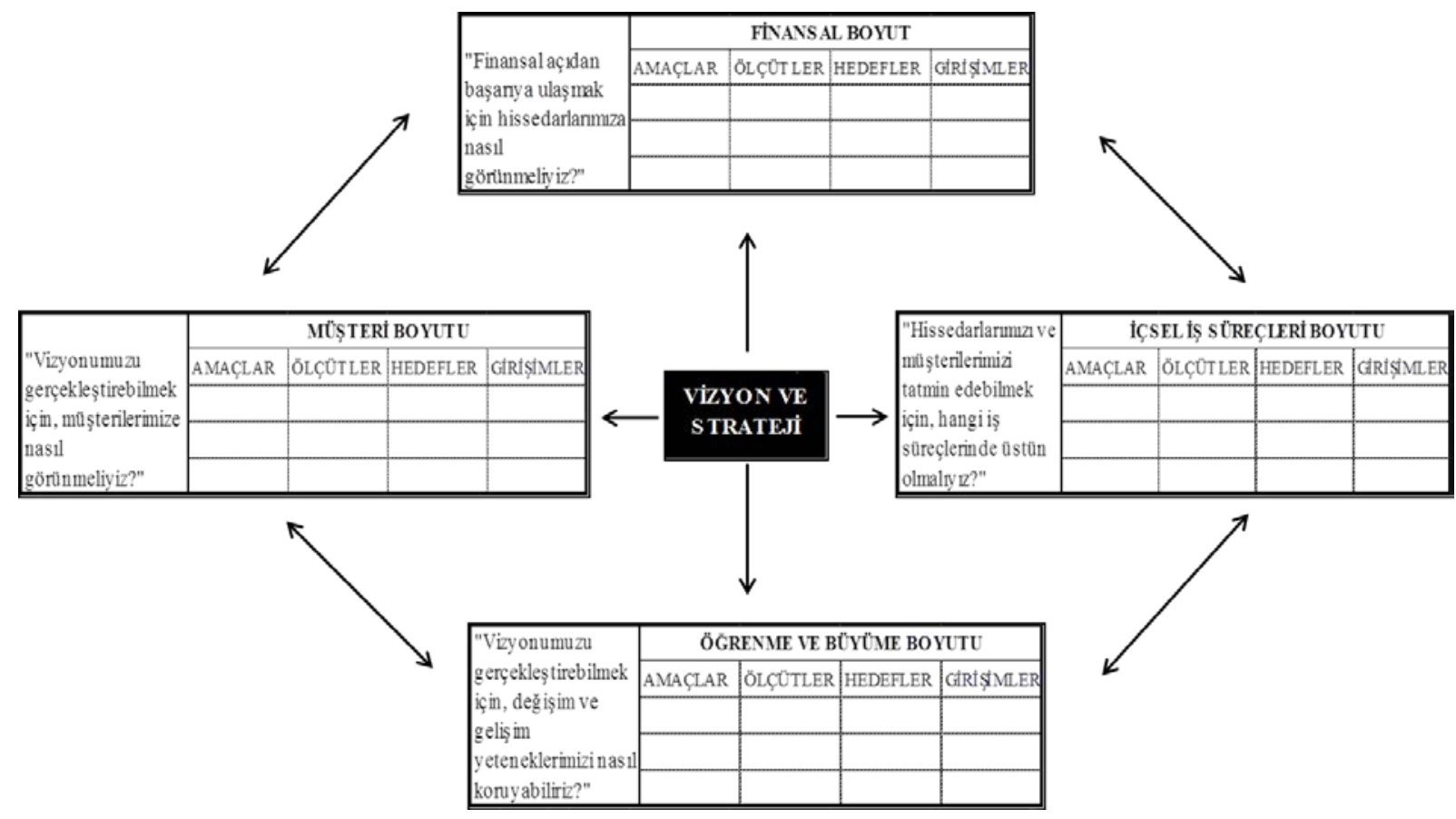

Kaplan ve Norton'un (1996b: 54) dört boyuta dayalı olarak geliştirdikleri ve strateji haritası adını verdikleri araç, örgütün tüm birimleri ve çalışanlar için genel ve anlaşılabilir bakış açısı oluşturmaktadır. Strateji haritası, bir şirketin stratejisi için yaşamsal önem taşıyan unsurları ve bunlar arasındaki ilişkileri ayrıntılı olarak göstermektedir. Strateji haritasının temelini oluşturan DPK'nın dört boyutu aşağıdaki gibi açıklanmaktadır.

\subsubsection{Finansal Boyut}

Finansal boyut, örgütsel stratejik hedeflere ulaşmada diğer DPK boyutlarının başarı derecelerini yansıtan tarihsel (gecikmeli) ölçütleri içermektedir. Finansal boyut, genellikle muhasebe verilerine dayanır. Diğer boyutlara ilişkin alınan kararlar nihayetinde finansal sonuçlar doğuracağı için, DPK boyutları hiyerarşisinde en tepede yer almaktadır (Bento vd., 2013: 51).

Kâr elde etmek için işletmeler finansal ihtiyaçlarını karşılamalı, bunun için de finansal kaynaklarını etkili ve verimli bir şekilde yönetmelidirler. Kaynaklarını etkin bir şekilde yönetemeyen örgütler, iflasa kadar gidebilecek finansal kayıp riski altındadırlar. Bu durum, finansal performans ölçütlerinin titiz kullanılması gerekliliğinin önemini göstermektedir (Upadhaya vd., 2014: 857).

DPK finansal hedefleri açık ve anlaşılır bir şekilde ifade eder ve işletmelerin yaşam süreçlerinin her farklı aşaması için özel finansal hedefler belirlenmesine yardımcı olur. Finansal boyutta yer alan etkenler, içinde bulunulan sektöre, çevreye ve işletmenin stratejisine özel etkenlerdir. Böylece DPK işletmelere, etkin fayda sağlamak ve risk yönetimi gibi konular 
arasından kendi finansal hedeflerini seçebilecekleri bir sınıflandırma şeması sunmaktadır (Yükçü, 2014: 665).

\subsubsection{Müşteri Boyutu}

Müşteri boyutu, örgütsel stratejinin hedef müşteri kitleleri için belirlediği değer önerilerini ölçmektedir (Bento vd., 2013: 51). Herhangi bir iş stratejisinin temeli, şirketin sunduğu ürün, fiyat, hizmet, ilişki ve imajın özgün bileşimini ifade eden müşteri değer önerisidir (Kaplan ve Norton, 2001: 93). Müşteri değer önerisi, hedef müşteri kitlesini etkilemek, bu kitleyi elinde tutmak ve bu kitleyle ilişkileri derinleştirmek amaçlarına yönelik olarak işletmenin kendisini rakiplerinden nasıl farklılaştırdığını tanımlar. Değer önerisi, işletmenin iç süreçlerini müşterilerle ilişkili sonuçlara bağlamaya yardımcı olduğu için çok önemlidir. Müşteri boyutunu oluşturma işlemlerinin sonucunda, yöneticilerin hedef pazar ve müşteri kesimleri ve bu hedef kesimler için seçilen temel sonuç ölçüleri - pazar ve müşteri payı, müşteri kazanma, tatmin ve kârlılık - ile ilgili kesin fikirler edinmiş olmaları gerekir (Yükçü, 2014: 665). Bu boyutun temel çıktı ölçütleri; müşteri memnuniyeti, müşteriyi elde tutma, yeni müşteri elde etme, müşteri kârlılı̆̆ı ve pazar payıdır (Kaplan ve Norton, 1996: 26).

\subsection{3. İçsel İş Süreçleri Boyutu}

İçsel iş süreçleri boyutu, örgütlerin müşteri değeri sunmak amacıyla iyi gerçekleştirmek zorunda oldukları temel iş süreçlerini kapsar (Bento vd., 2013: 50). Yöneticiler bu boyutta, hissedarlara ve müşterilerine yönelik amaçları gerçekleştirmek için mükemmel bir şekilde yerine getirilmesi gereken önemli süreçlerin neler olduğunu belirlerler. İçsel iş süreçleri, hedef pazarda müşterileri çekecek ve kalmalarını sağlayacak değer önerilerini sunmalı ve başarılı finansal sonuçlar elde edilmesine ilişkin paydaş beklentilerini karşılamalıdır (Kaplan ve Norton, 1996: 26).

İşletmenin içsel süreçlerle ilgili yapması gerekenler; yeni mamullerin geliştirilmesi ve yeni pazarlara ulaşmak için yeniliğin teşvik edilmesi, mevcut müşterilerle olan ilişkilerin geliştirilmesi, iç süreçlerin geliştirilmesi, kaynak-kapasite yönetimi, dışsal çıkar gruplarıyla iyi ve etkin ilişkiler kurulması olmalıdır.

\subsection{4. Öğrenme ve Büyüme Boyutu}

Öğrenme ve büyüme boyutu, işletmenin uzun vadeli büyüme ve gelişim için oluşturmak zorunda olduğu altyapıyı ifade etmektedir (Kaplan ve Norton, 1996c: 28). Finansal boyut, müşteri boyutu ve içsel iş süreçleri boyutuyla ilgili hedeflerin gerçekleştirilmesi, işletmenin öğrenme ve büyüme yeteneklerine bağlıdır. Bu boyutta yöneticiler, bir stratejiyi desteklemek için ihtiyaç duyulan çalışan yeteneklerini ve becerilerini, teknolojiyi ve kurumsal iklimi tanımlarlar. Daha üstün performansa ihtiyaç duyulan stratejiler, genellikle kişiler, sistemler ve kurumsal yeteneklerin artmasını sağlayacak işlemler için önemli ölçüde yatırım yapılmasını gerektirecektir (Yükçü, 2014: 667). Bu altyapı işletmenin insan kaynaklarını ve bilgi teknolojilerini, önemli iş süreçleriyle, 
farklılaştırılmış değer önerileriyle ve müşteri ilişkilerine ilişkin stratejik gereksinimlerle uyumlu hale getirir (Kaplan ve Norton, 2001: 94).

\subsection{Performans Boyutlarının Birbirleriyle Etkileşimi}

Finansal ve finansal olmayan ölçütlerin birlikte kullanıldığı tek performans ölçüm sistemi DPK değildir. Performans Ölçüm Matrisi, Performans Ölçüm Anketi, Performans (SMART) Piramidi, Sonuçlar ve Belirleyiciler Modeli, Dinamik Performans Ölçüm Modeli, Performans Prizması ve Tableau de Bord gibi başka çok boyutlu performans ölçüm sistemleri de bulunmaktadır. DPK'yı farklılaştıran unsur, performans boyutları arasındaki ilişkidir.

DPK ölçütleri, “dört bağımsız boyutun performans göstergeleri” değil, "dört boyutun hedefleri arasındaki bir dizi sebep-sonuç bağlantıları” olarak görülmelidir. Her bir boyutta gerçekleştirilen performansın birbirine bağlı sonuçlar oluşturduğu hiyerarşik model, strateji haritasında gösterilir.

Öğrenme ve büyüme boyutundaki gelişmeler (hiyerarşide en alt seviye) daha iyi içsel iş süreçlerinin oluşmasını sağlar (ikinci seviye), bu da müşterilere sağlanan değer önerilerini arttırır (üçüncü seviye), ve bu durum finansal performansı zirveye taşır (en üst seviye). Amaç, örgütsel stratejinin hikayesini anlatmak için eyleme geçirilebilir bir dizi tutarlı ölçümler ortaya koymaktır (Bento vd., 2013: 47).

DPK boyutları arasındaki stratejik bağlantılar strateji haritasında gösterilir ve "ise - o halde” önermeleri kullanılarak stratejinin test edilmesi sağlanır. Böylece, her bir finansal olmayan ölçütte gerçekleştirilen sürekli iyileştirmelerin finansal performansa etki edip etmediği izlenebilir. Örneğin, bir perakendecinin internet üzerinden satış yapma yönündeki bilgi teknolojisi yatırımı (öğrenme ve büyüme boyutu içinde bir başarı), daha hızlı ve daha doğru sipariş karşılamayı (içsel iş süreçleri boyutu içinde önemli bir iş süreci) sağlayabilir. Bunun sonucu olarak pazar payı (müşteri boyutu ölçütü) ve satış gelirleri (finansal ölçüt) artabilir. Öte yandan, yapılan yatırımın sonucu olarak finansal performansta bir gelişme yaşanmıyorsa, yöneticiler strateji haritasını yeniden çizmek için ihtiyaç duydukları bilgiyi geribildirim döngüsüyle alırlar (Bento vd., 2013: 47).

\section{BİR DENETIMM ŞİRKETİNDE DENGELİ PUAN KARTI İLE PERFORMANS ÖLÇÜMÜ UYGULAMASI}

$\mathrm{Bu}$ çalışmada, DPK yaklaşımıyla bir denetim şirketinde performans ölçümü uygulaması yapılmıştır.

\subsection{Araştırmanın Amacı ve Kapsamı}

Hizmet sektöründe müşteri portföyünü belirleyen ve sadık müşteriler oluşmasını sağlayan en önemli unsur hizmetin kalitesidir. Bu nedenle rekabete önem veren bir denetim şirketinin performans ölçümünü iyi bir şekilde yapması gerekmektedir. Müşteri memnuniyeti, çalışan memnuniyeti, finansal performans gibi ölçütler, bir denetim şirketinin işinin kalitesinin ölçülmesinde kullanılabilecek en önemli kriterlerdir. Çalışmada, denetim 
şirketlerinde performansın çok boyutlu olarak ölçülmesi amacı doğrultusunda bir denetim şirketinde DPK uygulaması yapılmıştır.

Türkiye'de DPK uygulamalarına ilişkin olarak; üretim sektöründe (Köse, 2007; Tanç, 2012; Yıldız vd., 2010; Hatunoğlu vd., 2014, Coşkun, 2006, Uygur, 2009, Kuğu ve Kırlı, 2013), sağlık sektöründe (Karsavuran, 2013; Yıldız vd., 2013, Uçkun ve Şahin, 2016), turizm sektöründe (Gençay, 2014; Bertan, 2009), lojistik sektöründe (Cebeci, 2012), eğitim sektöründe (Erkul vd., 2015) ve havacılık sektöründe (Gencer ve Çetin, 2011) çalışmalar yapılmıştır. Görüldüğü gibi, Türk literatüründe DPK'nın denetim sektöründe kullanımına ilişkin bir çalışma yer almamaktadır. Bu bağlamda, bu çalışmanın mevcut boşluğu doldurarak katkı sağlaması beklenmektedir.

Araştırma kapsamındaki denetim şirketinin vizyon, misyon ve stratejileri göz önüne alınarak DPK boyutlarının kapsamları belirlenmiş, performans ölçümü yapılmış ve sonuçlar değerlendirilmiştir. Söz konusu şirket, uluslararası nitelikte olup, İzmir, İstanbul ve Ankara dahilinde 900 kişilik denetim ekibine sahiptir. Araştırma yalnızca İzmir ofisini kapsamakta ve 2015 y1lı verilerini içermektedir.

\subsection{Araştırmanın Metodolojisi}

Çalışma kapsamındaki denetim şirketi için performans ile ilgili boyutlara ve verilere ulaşmada yüz yüze görüşme ve belge incelemesi metotları uygulanmıştır. Katılımcıların belirlenmesinde, tesadüfi olmayan örnekleme yöntemlerinden amaçlı örnekleme yöntemi kullanılmış, vergi denetimi ve bağımsız denetim bölümlerinde görev alan müdür, kıdemli müdür, direktör ve partnerlerle görüşülmüştür. Görüşmeler yöneticilerin iş yoğunluğu açısından uygun oldukları zamanlarda randevu alınarak gerçekleştirilmiş, toplam iki hafta sürmüştür. Yapılandırılmış birebir görüşme tekniği kullanılmıştır. Görüşme verileri elle kaydedilmiştir. Çalışmada, yüz yüze görüşmelerden elde edilen bilgilerin yanı sıra 2015 yılına ilişkin şirketin hazırladığı performans değerlendirme formlarında yer alan bilgilerden de faydalanılmıştır.

Yöneticilerle yapılan yüz yüze görüşmeler ve şirket içinde kullanılan performans değerlendirme formları dikkate alınarak, denetim şirketi için DPK'nın tüm boyutları ortaya konulmuştur. Her bir boyuta ilişkin olarak amaçlar belirlenmiş, belirlenen amaçlara ilişkin ölçütler oluşturulmuş ve sayisal performans hedefleri belirlenmiştir. Performans değerlendirme formlarından ve yöneticilerden elde edilen 2015 y1lına ilişkin fiili performans verileri hedeflenen performansla karşılaştırılmış, belirlenen hedeflere ulaşı1ıp ulaşılmadığ ölçülmüştür. Çalışmanın, denetim şirketlerinin performansının çok boyutlu olarak değerlendirilmesinde ilgililere yol göstereceği umulmaktadır.

\subsection{Araştırmanın Bulguları}

Araştırmanın katılımcılarına ilişkin bulgular ve DPK uygulamasına ilişkin bulgular aşağıda yer almaktadır. 


\subsubsection{Katılımcılara İlişkin Bulgular}

Araştırma denetim şirketinin İzmir ofisini kapsadığı için, katılımcılar bu ofiste görev alan yöneticilerdir. 3 partner, 1 direktör, 5 kıdemli müdür ve 5 müdür olmak üzere toplam14 yöneticiyle görüşülmüştür. Görüşülen yöneticilerden 10'u erkek 4'ü kadındır. Ayrıca, 9'u lisans, 5’i yüksek lisans derecesine sahiptir.

\subsubsection{Denetim Şirketinin Dengeli Puan Kartına İlişsin Bulgular}

Uygulamada öncelikle, her DPK boyutu için araştırmaya konu denetim şirketi için belirlenen amaçlar ve bu amaçlara ulaşmadaki performansı belirlemek için kullanılan ölçütler belirlenmiş, daha sonra her bir ölçüt için belirlenen performans hedefleri ile 2015 yılında gerçekleşen fiili performans karşılaştırılarak sonuçlar ortaya konmuştur.

\subsubsection{Dengeli Puan Kartı Boyutları}

Araştırmaya konu olan denetim şirketi için, her bir DPK boyutuna ilişkin belirlenen amaçlar ve ölçütler aşağıda açıklanmaktadır

\subsection{Finansal Boyut}

Finansal ölçütlerin belirlenmesinde, şirketin içinde bulunduğu sektör, ekonomik çevre ve rekabetçi pozisyonu incelenmiştir. İşletmenin; kârlılığı arttırmak, büyümek, verimliliği arttırmak, sözleşme fiyatlarını arttırmak ve masrafların müşterilere doğru olarak dağıtılması olarak belirlenen amaçlarına ilişkin finansal ölçütler Tablo 1'de yer almaktadır.

Tablo 1: Finansal Boyut için Amaçlar ve Ölçütler

\begin{tabular}{|l|l|}
\hline Amaçlar & Ölçütler \\
\hline Kârlılı̆̆ arttırmak & Kârdaki yıllık artı̧̧ \\
\hline Büyümek & Müşteri sayısı \\
\hline Verimliliği arttırmak & Denetim süreleri \\
\hline Sözleşme fiyatlarının arttırmak & Sözleşme ücretini enflasyon oranına göre belirlemek \\
\hline Masrafların doğru dağıtılması & Müşterinin masraflara itiraz etmemesi \\
\hline
\end{tabular}

\subsection{Müşteri Boyutu}

Denetim şirketlerinin yaşadığı en büyük problemlerin başında yeni müşteri bulmak ve mevcut müşterilerini elde tutmak gelmektedir. Söz konusu denetim şirketi, müşteri boyutu açısından bu problemleri göz önüne alarak, yeni müşteri bulmak, müşteri memnuniyetini ve müşteri sadakatini arttırmak olmak üzere üç adet hedef belirlemiştir. Bu hedeflere ilişkin ölçütler Tablo 2’de verilmektedir.

Tablo 2: Müşteri Boyutu için Amaçlar ve Ölçütler

\begin{tabular}{|l|l|}
\hline Amaçlar & Ölçütler \\
\hline Yeni müşteri bulma & Yıllık yeni müşteri sayısı \\
\hline Müşteri memnuniyeti & Hatasız ve kaliteli denetim \\
\hline Müşteri sadakati & $\begin{array}{l}\text { Yeni sözleşme döneminde kazanılan ve kaybedilen } \\
\text { müşteri sayısı }\end{array}$ \\
\hline
\end{tabular}




\subsubsection{3. İçsel İş Süreçleri Boyutu}

İçsel iş süreçleri kapsamında denetim şirketi için en önemli kriter, projenin getirisi ve proje için harcanan zamandır. Denetim şirketinde çeşitli kademelerde çalışan kişilerin projenin getirisine göre planlanması söz konusudur. Örneğin, maliyeti yüksek bir çalışan getirisi düşük bir proje için çok fazla zaman harcamamalıdır. Bu durum dikkate alındığında, içsel iş süreçleri için, zaman-maliyet ve süreç geliştirme olmak üzere iki amaç saptanmıştır. Bu amaçlar ve ölçütleri Tablo 3’te yer almaktadır.

Tablo 3: İçsel İş Süreçleri için Amaçlar ve Ölçütler

\begin{tabular}{|l|l|}
\hline Amaçlar & Ölçütler \\
\hline Zaman-Maliyet & Projeye harcanan zaman ve maliyet oranı \\
\hline Süreç geliştirme & Hata oranında azalma \\
\hline
\end{tabular}

\subsubsection{4. Öğrenme ve Büyüme Boyutu}

Şirket, hizmet sektöründe faaliyet gösteren global bir şirket olması nedeniyle öğrenme boyutu oldukça önem arz etmektedir. Kendini yenileyemeyen bir denetim şirketi kuşkusuz rekabet gücünü yitirecektir. Bu nedenledir ki, şirket için hayati önem taşıyan büyüme ve öğrenme boyutuna ilişkin kriterler belirlenirken çalışanların sürekli olarak gelişmesine yönelik amaçlar ön planda tutulmuştur. Çalışanların yeteneklerinin geliştirilmesi, teknik bilgilerinin arttırılması, akademik faaliyetlerde bulunmaları ve çalışan motivasyonu şirket için belirlenen öğrenme ve büyüme kriterleridir. $\mathrm{Bu}$ amaçlar doğrultusunda belirlenen ölçütler Tablo 4'te verilmektedir.

Tablo 4: Öğrenme ve Büyüme Boyut için Amaçlar ve Ölçütler

\begin{tabular}{|l|l|}
\hline Amaçlar & Ölçütler \\
\hline Çalışanların yeteneklerinin geliş̧tirilmesi & Şirket içi eğitimler \\
\hline Çalışanların teknik bilgilerinin arttırılması & Haftalık teknik toplantılar \\
\hline Çalışanların akademik faaliyetlerde bulunmaları & Yıllık makale vb. sayısı \\
\hline Çalışan motivasyonu & Çalışanın kurum bağlılığının incelenmesi \\
\hline
\end{tabular}

\subsubsection{Dengeli Puan Kartı Ölçüm Sonuçların Değerlendirilmesi}

Şirketin performans boyutlarına göre belirlenen amaçlar ve ölçütler dikkate alınarak, boyutlardaki her bir amaç için ayrı performans hedefleri belirlenmiştir. Daha sonra, yüz yüze görüşmeler ve belge incelemeleri sonucunda elde edilen veriler ile hedefler karşılaştırılmıştır. Sonuçlar Tablo 5’te verilmektedir.

Belirlenen ölçütlere ilişkin hedeflenen durum ile gerçekleşen sonuçlar karşılaştırıldığında oldukça olumlu bir tablo karşımıza çıkmaktadır. 
Tablo 5: Dengeli Puan Kartı Ölçüm Sonuçları

\begin{tabular}{|c|c|c|c|}
\hline Amaçlar & Ölçütler & Hedef & Gerçekleşen \\
\hline \multicolumn{4}{|c|}{ FINANSAL BOYUT } \\
\hline Kârlılığı arttırmak & Kârdaki yıllık artış & $\% 10$ & $\% 7$ \\
\hline Büyümek & Müşteri say1s1 & $\% 15$ & $\% 17$ \\
\hline Verimliliği arttırmak & Denetim sürelerini azaltmak & $\% 20$ & $\% 5$ \\
\hline $\begin{array}{l}\text { Sözleşme fiyatlarının } \\
\text { arttırılması }\end{array}$ & $\begin{array}{l}\text { Sözleşme ücretini enflasyon } \\
\text { oranına göre belirlemek }\end{array}$ & $\% 20$ & $\% 12$ \\
\hline \multicolumn{4}{|c|}{ MÜŞTERİ BOYUTU } \\
\hline Yeni müşteri bulma & Yıllık yeni müşteri sayısı & 20 & 23 \\
\hline Müşteri memnuniyeti & Hatasız ve kaliteli denetim & $\% 95$ & $\% 98$ \\
\hline Müşteri sadakati & $\begin{array}{l}\text { Yeni sözleşme döneminde } \\
\text { kazanılan ve kaybedilen } \\
\text { müşteri sayısı }\end{array}$ & 20 kazanılan-5 kaybedilen & $\begin{array}{l}23 \text { kazanılan-8 } \\
\text { kaybedilen }\end{array}$ \\
\hline \multicolumn{4}{|c|}{ İÇSEL İŞ SÜREÇLERİ BOYUTU } \\
\hline Zaman-Maliyet & $\begin{array}{l}\text { Projeye harcanan zaman ve } \\
\text { maliyet oranı }\end{array}$ & 250 saat-350saat/yıllık & 370 saat/yıllık \\
\hline Süreç geliştirme & Hata oranında azalma & $\begin{array}{c}\text { \%5 kabul edilebilir hata } \\
\text { oranı }\end{array}$ & $\% 3$ hata oran 1 \\
\hline \multicolumn{4}{|c|}{ ÖĞRENME VE BÜYÜME BOYUTU } \\
\hline $\begin{array}{l}\text { Çalışanların } \\
\text { yeteneklerinin } \\
\text { geliştirilmesi } \\
\end{array}$ & Şirket içi eğitimler & Y1lda 10 adet genel eğitim & $\begin{array}{c}\text { Y1lda } 10 \text { adet genel } \\
\text { eğitim }\end{array}$ \\
\hline $\begin{array}{l}\text { Çalışanların teknik } \\
\text { bilgilerinin arttırılması }\end{array}$ & Haftalık teknik toplantılar & 40 hafta & 40 hafta \\
\hline $\begin{array}{l}\text { Çalışanların akademik } \\
\text { faaliyetlerde bulunmaları }\end{array}$ & Yıllık makale vb. sayısı & Min. 4 makale & 1 makale \\
\hline Çalışan motivasyonu & $\begin{array}{l}\text { Çalışanın kurum bağlılığının } \\
\text { incelenmesi }\end{array}$ & $\% 70$ & $\% 80$ \\
\hline
\end{tabular}

Finansal boyut ele alındığında; şirketin \%10 olarak belirlediği kârlılık artışının \%7 seviyesinde kaldığı görülmektedir. Ancak piyasadaki rekabet koşulları, rakiplerin belirlenen fiyatların çok altında sözleşme yapıyor olmaları gibi etkenler göz önüne alındığında \%7'lik kârlılık oranın oldukça başarılı olduğu anlaşılmaktadır. Şirketin yeni dönemde müşteri sayısını tahmin ettiğinden daha fazla arttırdığı görülmektedir. Bu da şirketin iyi bir pazarlama stratejisine ve iyi bir hizmet kalitesine sahip olduğunu göstermektedir. Denetim sürelerinin kısaltılması konusunda ise tahmin edilen oranın çok altında kalındığı açıkça görülmektedir. Bu noktada işletmenin denetim sürecini ve denetim elemanlarını gözden geçirmesi gerektiği sonucuna varılmaktadır. Sözleşme fiyatlarında da şirket istediği sonuca ulaşamamıştır. Ancak yukarıda söz edildiği gibi piyasadaki rekabet koşulları nedeniyle, bir başka ifadeyle dışsal nedenlerden dolayı bu sonucun ortaya çıktığını söylemek yerinde olacaktır.

Müşteri boyutuna bakıldığında; şirketin bu boyut için belirlemiş olduğu tüm hedeflerin aş1ldığ 1 görülmektedir. Yeni müşteri bulma ve müşteri sadakati amaçları birbirine paralel bir seyir izlemiştir. Ayrıca mevcut müşterilerin de hizmet kalitesinden memnuniyet duydukları anlaşılmaktadır. 
İçsel iş süreçleri boyutunda, zaman-maliyet dengesinin şirket için az da olsa problem yarattığı anlaşılmaktadır. Proje başına harcanan zaman ile proje için katlanılan maliyetler arasında istenilen hedefe ulaşılamamıştır. Burada proje için harcanan denetim süresinin de etkili olduğunu söylemek hatalı olmayacaktır. Süreç geliştirmeye bakıldığında, \%5 olarak hedeflenen hata payının gerçekte \%3 olarak gerçekleşmesi şirketin hizmet kalitesinin arttığının bir göstergesidir.

Öğrenme ve büyüme boyutu ele alındığında; yıllık eğitimler ve teknik toplantıların hedeflenen şekilde gerçekleştiği görülmektedir. Çalışan motivasyonu ise şirket içinde yapılan anket sonuçlarına göre hedeflenenden daha yüksek gerçekleşmiştir. Şirketin global bir şirket olması, patron baskısının olmaması ve esnek çalışma saatlerinin çalışan motivasyonu üzerinde olumlu etkisinin olduğu söylenebilir. Ancak çalışanlardan beklenen akademik faaliyetlerinin hedeflenenin çok altında kaldığı görülmektedir. Bu konuda denetim sektörünün iş yoğunluğunun etkili olduğu düşünülmektedir.

\section{SONUÇ}

Performans ölçümü pek çok kişi tarafından, davranışı kontrol etmek ve geçmiş performansı değerlendirmek için kullanılan bir araç olarak tanımlanmaktadır. Gerçekten de geleneksel kontrol ve performans ölçüm sistemleri, bireylerin ve örgütsel birimlerin önceden belirlenmiş bir plan ile uyumlu olmalarını sağlama amacı gütmektedirler. DPK kapsamında yapılan ölçümün amacı ise, işletme stratejisini açıkça ortaya koymak ve ortak bir hedefe ulaşmak için bireysel ve örgütsel girişimleri uyumlu hale getirmeye yardımcı olmaktır. $\mathrm{Bu}$ bağlamda DPK, geleneksel bir kontrol sistemi değil, bir iletişim, bilgi ve öğrenme sistemidir. Ancak DPK'nın bu şekilde kullanılabilmesi ve rekabetçi bir başarı elde edilebilmesi için, ölçütlerin işletmenin uzun vadeli stratejisini temsil etmeleri ve yönetim sistemine entegre olmaları gerekmektedir. Başarılı bir DPK uygulaması, bir ölçüm projesi değil, bir değişim projesi olmalıdır.

DPK, her işletmenin kendine özgü yapısı dikkate alınarak oluşturulması gereken bir modeldir. İşletmenin vizyon, misyon ve hedefleri DPK'nın dört boyutuna göre şekillenmekte ve yenilenmektedir. DPK, işletmelerde hedeflerin daha gerçekçi olarak belirlenmesine, dikey ve yatay iletişimin gelişmesine ve kurumsal performansın artmasına olanak tanır.

Çalışmada, bir denetim şirketinin DPK ile performans ölçümü yapılmıştır. Özellikle hizmet sektöründe sadece finansal değil finansal olmayan birçok verinin de dikkate alınması, analiz edilmesi ve performansın çok boyutlu olarak ölçülmesi önem taşımaktadır. Söz konusu denetim şirketinin çok boyutlu olarak incelenmesi sonucunda, her boyut için belirlenen hedeflere ulaşma derecesinin birtakım eksiklikler taşımasına rağmen oldukça yüksek olduğu söylenebilir. Şirketin bu veriler 1şığında gelecek hedeflerini belirlemesi eksiklerini tamamlamak için çözüm yolları geliştirmesi gerekmektedir.

Hizmet sektöründeki yoğun rekabet koşulları dikkate alındığında performans ölçümünün ne kadar önemli olduğu, performans sonuçlarına göre şirketlerin strateji ve 
hedefler belirlemesi gerektiği, gerektiğinde ivedilikle bu strateji ve hedeflerde değişiklik yapılabilmesi göz önüne alındığında, çok boyutlu performans ölçüm yöntemlerinden DPK uygulamasının arttırılması gerektiği düşünülmektedir.

Literatürde DPK uygulamalarına ilişkin olarak yapılmış pek çok çalışma mevcuttur. Bu çalışmanın, bu konuda yapılmış önceki çalışmalarda yer almayan bir sektör olan denetim sektörüne odaklanmasıyla literatüre katkı sağlayacağı düşünülmektedir. Çalışmanın kısıtları, uygulamanın tek bir şirkette yapılması ve tek bir yılı içermesidir. Gelecekte yapılacak çalışmalarda, bir şirketin birden çok yılını kapsayan bir uygulama yapılması, söz konusu şirketin performansını dönemler arasında karşılaştırma imkânı verecektir. Ayrıca, uygulama yapılan şirket sayısının arttırılması, şirketlerin performanslarının birbirleriyle karşılaştırılmasını mümkün kılacaktır. Bu sayede şirketlerin birbirlerine göre güçlü ve zayıf yönleri görünür hale gelecek ve stratejik adımların atılması açısından önemli bir bulgu edinilecektir.

\section{KAYNAKLAR}

Akgül, Başak A. (2004), “İşletmelerde Yeni Performans Ölçümleme Sistemleri”, Muhasebe ve Finansman Dergisi, 24, ss. 73-82.

Atkinson, Anthony A. - Kaplan, Robert S. - Matsumura, Ella M. - Young, Mark S. (2012), Management Accounting: Information for Decision-Making and Strategy Execution, Pearson Education (6. bask1), New Jersey.

Aureli, Selena. (2010), “The Introduction of Innovative Performance Measurement and Management Control Systems: The Role of Financial Investors and Their Acquired Companies”, Epstein, Marc J. - Manzoni, Jean-François - Davila, Antonio (Ed.), Performance Measurement and Management Control: Innovative Concepts and Practices, Emerald Group Publishing, Bingley pp. 81-114.

Ax, Christian - Bjornenak, Trond. (2005), "Bundling and Diffusion of Management Accounting Innovations-The Case of the Balanced Scorecard in Sweden", Management Accounting Research, 16(1), pp. 1-20.

Bento, Al - Bento, Regina - White, Lourdes F. (2013), "Validating Cause-and-Effect Relationships in the Balanced Scorecard”, Academy of Accounting and Financial Studies Journal, 17(3), pp. 45-55.

Bertan, Serkan. (2009), “Otel İşletmelerinde Yönetim Aracı Olarak Kurumsal Karne”, Journal of Yasar University, 4(16), ss. 2525-2538.

Bititci, Umit S. - Carrie, Allan S. - McDevitt, Liam. (1997), "Integrated Performance Measurement Systems: A Development Guide”, International Journal of Operations \& Production Management, 17(5), pp. 522-535.

Budde, Jörg. (2007), “Performance Measure Congruity and the Balanced Scorecard”, Journal of Accounting Research, 45(3), pp. 515-539. 
Cebeci, C. (2012), “Lojistikte Dengeli Skor Kartının Uygulanabilirliği: Teorik Çerçeve”, Erciyes Üniversitesi İktisadi ve İdari Bilimler Fakültesi Dergisi, 40, s. 21-41.

Chenhall, Robert H. - Langfield-Smith, Kim. (1999), “The Implementation of Innovative Management Accounting Systems”, Australian Accounting Review, 9(19), pp. 37-46.

Coşkun, Ali. (2006), "Stratejik Performans Yönetiminde Performans Karnesi Kullanımı: Türkiye'deki Sanayi İsletmeleri Üzerine Bir Araştırma”, Muhasebe Bilim Dünyası Dergisi, 8(1), ss. 127-153.

Erkul, Hüseyin - Dereköy, Feyza - Ayhün, Sena E. (2015), "Yükseköğretim Kurumlarında Dengeli Ölçüm Kartı Geliştirilmesi: Çanakkale Sosyal Bilimler Meslek Yüksekokulu Örneğii”, Yükseköğretim ve Bilim Dergisi, 5(2), ss. 203-213.

Evan, William M. (1976), “Organizational Theory and Organizational Effectiveness: An Exploratory Analysis”, Spray, S. Lee (Ed.), Organisational Effectiveness: TheoryResearch-Utilization, Kent State University Press, Ohio, pp. 15-28.

Gencer, Cevriye - Çetin, Tuğba. (2011), "Kurumsal Performans Karnesi ve Havacılık Sektöründe Bir Uygulama”, Savunma Bilimleri Dergisi, 10(2), ss. 105-121.

Gençay, İ. Cemal. (2014). "Termal Turizm İşletmelerinde Kurumsal Performans Karnesi Oluşturulmasına Yönelik Model Önerisi”, Seyahat ve Otel İşletmeciliği Dergisi, 11(1), ss. 70-89.

Gomes, Carlos F. - Yasin, Mahmoud M. - Lisboa, Joao V. (2004), “A Literature Review of Manufacturing Performance Measures and Measurement in an Organizational Context: A Framework and Direction for Future Research”, Journal of Manufacturing Technology Management, 15(6), pp. 511-530.

Hatunoğlu, Zeynep - Kaba, Mehmet - Kı1l1, Mustafa. (2014), “İşletmelerde Performans Ölçme ve Değerlendirme Aracı Olarak Dengeli Sonuç Kartı (Balanced Scorecard): Kahramanmaraş’ta Örnek Bir Uygulama”, Uludağ Üniversitesi İktisadi ve İdari Bilimler Fakültesi Dergisi 33(1),s s. 71-94.

Kanji, Gopal K. (2002), “Performance Measurement System”, Total Quality Management, 13(5), pp. 715-728.

Kaplan, Robert S. - Norton, David P. (1992), “The Balanced Scorecard - Measures that Drive Performance”, Harvard Business Review, 70(1),pp. 71-79.

Kaplan, Robert S. - Norton, David P. (1996a), "Using the Balanced Scorecard as a Strategic Management System”, Harvard Business Review, 74(1), s. 75-85.

Kaplan, Robert S. - Norton, David P. (1996b), “Linking the Balanced Scorecard to Strategy”, California Management Review, 39 (1), pp. 53-79.

Kaplan, Robert S. - Norton, David P. (1996c), The Balanced Scorecard: Translating Strategy into Action, Harvard Business School Press, Boston. 
Kaplan, Robert S. - Norton, David P. (2001), “Transforming the Balanced Scorecard from Performance Measurement to Strategic Management: Part I”, Accounting Horizons, 15(1), pp. 87-104.

Kaplan, Steven E. - Petersen, Michael J. - Samuels, Janet A. (2012), “An Examination of the Effect of Positive and Negative Performance on the Relative Weighting of Strategically and Non-Strategically Linked Balanced Scorecard Measures”, Behavioral Research in Accounting, 24(2), pp. 133-151.

Karsavuran, Seda. (2013), "Stratejik Değerlendirme ve Kontrol: Dengeli Puan Kartı'nın Sağlık Hizmetlerinde Kullanımı”, Hacettepe Üniversitesi Sağlık İdaresi Dergisi, 16(2), ss. 69-89.

Kennerley, Mike - Neely, Andy. (2000), "Performance Measurement Frameworks - A Review”, Neely, Andy (Ed.), Business Performance Measurement: Theory and Practice, Cambridge University Press, Cambridge, pp. 145-155.

Kennerley, Mike - Neely, Andy. (2002), “A Framework of the Factors Affecting the Evolution of Performance Measurement Systems”, International Journal of Operations \& Production Management, 22(11), pp. 1222-1245.

Köse, Tunç. (2007), "Stratejik Bir Yapı Çerçevesinde Dengeli Ölçüm Kartı Tekniği (Balanced Scorecard) ve Bir Uygulama", Eskişehir Osmangazi Üniversitesi Sosyal Bilimler Dergisi, 8(1), ss. 201-220.

Kuğu, Tayfun D. - Kırlı Mustafa. (2013), "İşletme Performansının Değerlendirilmesinde Bir Yenilikçi Yönetim Muhasebesi Aracı Olarak Balanced Scorecard Uygulaması”, Süleyman Demirel Üniversitesi İktisadi ve İdari Bilimler Fakültesi Dergisi, 18(2), ss. 301-318.

McNair, Carol J. - Mosconi, William. (1987), "Measuring Performance in an Advanced Manufacturing Environment”, Management Accounting, 69(1), pp. 28-31.

Moullin, Max. (2007), "Performance Measurement Definitions: Linking Performance Measurement and Organisational Excellence”, International Journal of Health Care Quality Assurance, 20(3), pp. 181-183.

Otley, David. (2001), “Accounting Performance Measurement: A Review of Its Purposes and Practices”, International Journal of Business Performance Management, 3(2), pp. 245260.

Santori, Peter R. - Anderson, Alan D. (1987), "Manufacturing Performance in the 1990s: Measuring for Excellence”, Journal of Accountancy, 164(5), pp. 141-147.

Striteska, Michaela - Spickova, Marketa. (2012), "Review and Comparison of Performance Measurement Systems”, Journal of Organizational Management Studies, 19(3), pp. 277-294. 
Tanç, Şükran G. (2012), "Yeni Performans Ölçüm Yöntemleri (Faaliyete Dayalı Maliyetleme, Performans Karnesi ve Ekonomik Katma Değer) Entegrasyonu ve Örnek Bir Uygulama”, Trakya Üniversitesi Sosyal Bilimler Dergisi, 14(2), ss. 203-230.

Uçkun, Nurullah - Şahin, Ümit. (2016), "Kamu Hastaneleri Birlikleri Verimlilik Değerlendirmesinde Verimlilik Karnesi Uygulaması", International Journal of Social Sciences and Education Research, 2(1), ss. 370-383.

Upadhaya, Bedanand - Munir, Rahat - Blount, Yvette. (2014), “Association Between Performance Measurement Systems and Organisational Effectiveness”, International Journal of Operations \& Production Management, 34(7), pp. 853-875.

Uygur, Akyay. (2009), "Çok Boyutlu Performans Değerleme Modeli Olarak Dengeli Başarı Göstergesi Uygulaması”, Doğuş Üniversitesi Dergisi, 10(1), ss. 148-159.

Veltri, Stefania. (2011), "Is the Balanced Scorecard Appropriate to Measure Intangible Resources?”, The IUP Journal of Accounting Research \& Audit Practices, 10(3), pp. $7-24$.

Westphal, James D. - Gulati, Ranjay - Shortell, Stephen, M. (1996), “The Institutionalization of Total Quality Management: The Emergence of Normative TQM Adoption and the Consequences for Organizational Legitimacy and Performance”, Academy of Management Best Papers Proceedings, pp. 249-253.

Yıldız, M. Selami - Karagöz, Yalçın - Mesci, Muammer. (2010), "Performans Değerlendirme ve Süreç Yönetim Aracı Balanced Scorecard'nn Boyutlarına Katılım Düzeyi: Küçük ve Orta Ölçekli Sanayi İşletmelerinde Bir Araştırma", Atatürk Üniversitesi İktisadi ve İdari Bilimler Dergisi, 24(3), ss. 1-22.

Yıldız, M. Selami - Kethüda, Önder - Kurutkan, M. Nurullah. (2013), "Dengeli Ölçüm Kartı'nın Hastane İşletmelerinde Uygulanması: Örnek Olay Çalışması", Atatürk Üniversitesi İktisadi ve İdari Bilimler Dergisi, 27(4), ss. 90-109.

Yükçü, Süleyman. (2014), Herkes için Yönetim Muhasebesi, Altın Nokta Yayınevi, İzmir.

Yükçü, Süleyman - Atağan, Gülşah. (2010), "TOPSIS Yöntemine Göre Performans Değerleme”, Muhasebe ve Finansman Dergisi, 45, ss. 28-35. 